\title{
Is Emilin-1 a molecular link contributing to the extension of thoracic aortic aneurysm dissection and increasing the magnitude of the associated hypertension
}

\author{
Simon W Rabkin* \\ Department of Medicine, Division of Cardiology, University of British Columbia, Canada
}

Patients with acute aortic dissection, the dominant condition in acute aortic syndromes, have a high mortality [1]. Within types of thoracic aortic dissection, the more extensive the TAD the worse the prognosis [2]. Thus, factors influencing the extent of the TAD are important considerations. The initial presentation of acute aortic dissection is severe chest pain and hypertension. The presence of hypertension is a key element of thoracic aortic dissection (TAD) [3]. The hypertension in acute aortic syndromes is often severe and difficult to treat. From another perspective, a significant proportion of patients presenting to the emergency department with hypertensive crisis with severe blood pressure elevations have an aortic dissection [4].

Thus, refractory hypertension or high blood pressure which is difficult to control or treat, is a major component of acute aortic syndromes. Importantly hypertension is a significant independent predictor of in-hospital mortality in acute aortic syndromes after considering other factors in multivariate analysis [5]. The mechanism of the hypertension in this clinical setting has usually been attributed to severe chest pain and sympathetic activation. Recent data from proteomic analysis of thoracic aortic dissection suggests a new possible molecular mechanism that may lead to increases in both the extent of a $\mathrm{TAD}$ and the associated hypertension.

Proteomic analysis of aortic tissues from patients with aortic dissection and hypertension found that emilin-1 was down-regulated by approximately 2.3 fold compared to age and sex matched controls [6]. The data from protein screening was validated by Western blotting [6]. Degradation of proteins in the aortic wall would be anticipated from activation of enzymes such as matrix metalloproteases (MMP) in the aortic wall in aortic aneurysms leading to TAD [6-9]. Indeed, Emilin is a substrate for MMP as demonstrated by its release from human radial arteries incubated with different MMPs [10]. The degradation of Emilin-1 has potential implications as a factor altering the extent of the TAD and increasing the magnitude of the hypertension in acute aortic dissection.

Emilin (Elastin Microfibril Interface Located protein), first identified as a glycoprotein in the aorta of chick is associated with elastic fibers [11-12]. Human Emilin, or Emilin-1, consists of an $\mathrm{N}$-terminal signal peptide, a cysteine-rich domain, a coiled-coil motif, a collagen-like domain, and a C1q-like motif [13]. Emilin-1 is distributed in tissues where elastic recoil is a component of tissue function such as in the aorta [13]. Emilin-1 is localized at the interface between elastin and microfibrils in the artery and undoubtedly operates to facilitate the function of elastin [13] which plays an important role in arterial structure and function [14].
While the precise factor(s) initiating TAD is still debated, mechanical or functional failure of the aortic elastin is considered to predisposes to TAD and further aneurysmal dilatation [15]. EMILIN1-deficient aorta is associated with an increase in the space between the endothelial cell membrane and the internal elastic lamella as well as abnormal cell surface-elastic fiber connections for smooth muscle cells [16]. Degradation of Emilin-1 in the aorta in TAD limits the role of Emilin-1 to stabilize the molecular interactions between elastic fibers [16]. This would be anticipated to extend the dissection process and/or removes a constraint for aortic expansion.

Hypertension is not only a significant component of TAD [3] but is also an important predictor of TAD mortality [5]. Emilin-1 is a regulator of blood pressure as blood pressure is significantly increased in the absence of Emilin [17]. EMILIN-1 null mice have an increase in systolic blood pressure by $20 \mathrm{mmHg}$ compared to wild type mice and systolic blood pressure is increased $10 \mathrm{mmHg}$ in heterozygous animals [17]. Diastolic blood pressure is also elevated and the increase in blood pressure is attributable to an increase in vascular resistance [17]. This action of Emilin involves its ability to prevent pro Transforming Growth Factor - beta (TGF- $\beta$ processing to TGF- $\beta$ which occurs through proteolytic cleavage in the extracellular space [17]. Thus, a reduction of the ability of Emilin-1 to downregulate the production of TGF- $\beta$ increases TGF- $\beta$ and its effects on cell signalling in the vasculature. The role of TGF- $\beta$ in hypertension is complex [18] and suggests that the blood pressure elevation secondary to reduced Emilin may not be entirely attributable to its role on TGF- $\beta$. More importantly is the question how much local aortic destruction of Emilin-1 can be translated into increases in blood pressure which to date has been considered to operative in small resistance vessels [17]. The aorta does influence blood pressure mainly systolic blood pressure and TGF- $\beta$ can increase aortic stiffness [19] and to that extent can be a component of the hypertensive response to aortic dissection.

TGF- $\beta$ is involved in the development of aortic aneurysms as genetic defects in TGF- $\beta$ are associated with aortic aneurysms [20-21]. The precise role and molecular mechanisms underlying this relationship, however, has been characterized as elusive and controversial [22].

Correspondence to: Dr. Simon W. Rabkin MD, FRCPC, FCCS, FACC Department of Medicine, Division of Cardiology, University of British Columbia, Canada, Tel: 604875 5847; E-mail: rabkin@mail.ubc.ca

Received: November 03, 2016; Accepted: November 14, 2016; Published: November 18, 2016 
Rabkin SW (2016) Is Emilin-1 a molecular link contributing to the extension of thoracic aortic aneurysm dissection and increasing the magnitude of the associated hypertension

Enhanced TGF- $\beta$ signaling as well as TGF- $\beta$ receptor mutations have been implicated in in aneurysm formation [22-25]. It has been proposed that different cell types within the aortic wall responds differently to TGF- $\beta$ so that the balance of effects of TGF- $\beta$ in conjunction with other factors, dictate the net effect [23]. TGF- $\beta$-induced smooth muscle cell apoptosis and stimulates the differentiation of fibroblasts into myofibroblasts which accelerates aneurysm formation [8]. Gene mutations in TGF- $\beta$ can increase of TGF- $\beta$ signalling, as manifested by increased TGF- $\beta$ in the aorta and phosphorylation of targets such as SMAD2, ERK1/2, and Connective Tissue Growth Factor [20,21]. Overexpression of TGF- $\beta$ in Marfan's syndrome impacts various components of the arterial wall including hyaluronic synthesis and apoptosis which limit tissue repair and likely contribute to aneurysm expansion [26]. Thus, reduction in Emilin-1, a negative regulator of TGF- $\beta$ should lead to aortic expansion.

In summary, there is intriguing new data on a new molecular mechanism to account for an expansion of aortic dissection and the increase in blood pressure in aortic dissection. Direct testing of this linkage through acute administration of TBF- $\beta$ inhibitors may lead to an improvement in clinical management of TAD.

\section{Competing interests}

There are no conflicts of interest or any relationship with industry and financial associations that might pose a conflict of interest.

\section{References}

1. Mussa FF, Horton JD, Moridzadeh R, Nicholson J, Trimarchi S, et al. (2016) Acute Aortic Dissection and Intramural Hematoma: A Systematic Review. JAMA 316: 754 763. [Crossref]

2. Valentine RJ, Boll JM, Hocking KM, Curci JA, Garrard CL, Brophy CM, et al. (2016) Aortic arch involvement worsens the prognosis of type B aortic dissections. Journal of Vascular Surgery 64: 1212-1218. [Crossref]

3. Chan KK, Rabkin SW (2014) Increasing Prevalence of Hypertension Among Patients with Thoracic Aorta Dissection: Trends Over Eight Decades--A Structured Metaanalysis. American Journal of Hypertension 27: 907-917. [Crossref]

4. Pinna G, Pascale C, Fornengo P, Arras S, Piras C, Panzarasa P, et al. (2014) Hospital admissions for hypertensive crisis in the emergency departments: a large multicenter Italian study. PLOS ONE 9: e93542. [Crossref]

5. Trimarchi S, Eagle KA, Nienaber CA, Pyeritz RE, Jonker FH, Suzuki T, et al. (2010) Importance of refractory pain and hypertension in acute type B aortic dissection insights from the International Registry of Acute Aortic Dissection (IRAD). Circulation 122: 1283-1289. [Crossref]

6. Zhang K, Pan X, Zheng J, Xu D, Zhang J, Sun L (2015) Comparative tissue proteomics analysis of thoracic aortic dissection with hypertension using the iTRAQ technique. European Journal of CardioThoracic Surgery 47: 431-438. [Crossref]

7. Rabkin SW (2014) Differential Expression of MMP-2, MMP-9 and TIMP Proteins in Ascending Thoracic Aortic Aneurysm - comparison with and without Bicuspid Aortic Valve: a Meta-Analysis. VASA 43: 433-442. [Crossref]

8. Rabkin SW (2015) Accentuating and Opposing Factors Leading to Development of Thoracic Aortic Aneurysms Not Due to Genetic or Inherited Conditions. Frontiers in Cardiovascular Medicine 2: 21-29. [Crossref]
9. Zhang X, Wu D, Choi JC, Minard CG, Hou X, Coselli JS (2014) Matrix metalloproteinase levels in chronic thoracic aortic dissection. The Journal of Surgical Research 189: 348-358. [Crossref]

10. Stegemann C, Didangelos A, Barallobre-Barreiro J, Langley SR, Mandal K, Jahangiri M, et al. (2013) Proteomic identification of matrix metalloproteinase substrates in the human vasculature. Circ Cardiovasc Genet 6: 106-117. [Crossref]

11. Bressan GM, Castellani I, Colombatti A, Volpin D (1983) Isolation and characterization of a 115,000-dalton matrix-associated glycoprotein from chick aorta. The Journal of Biological Chemistry 258: 13262-13267. [Crossref]

12. Bressan GM, Daga-Gordini D, Colombatti A, Castellani I, Marigo V, Volpin D (1993) Emilin, a component of elastic fibers preferentially located at the elastin-microfibrils interface. The Journal of Cell Biology 121: 201-212. [Crossref]

13. Colombatti A, Doliana R, Bot S, Canton A, Mongiat M, Mungiguerra G, et al. (2000) The EMILIN protein family. Matrix Biol 19: 289-301. [Crossref]

14. Dingemans KP, Teeling P, Lagendijk JH, Becker AE (2000) Extracellular matrix of the human aortic media: an ultrastructural histochemical and immunohistochemical study of the adult aortic media. Anatomical Record 258: 1-14. [Crossref]

15. Pratt B, Curci J (2010)Arterial elastic fiber structure. Function and potential roles in acute aortic dissection. The Journal of Cardiovascular Surgery 51: 647-656. [Crossref]

16. Zanetti M, Braghetta P, Sabatelli P, Mura I, Doliana R, et al. (2004) EMILIN-1 deficiency induces elastogenesis and vascular cell defects. Mol Cell Biol 24: 638-650. [Crossref]

17. Zacchigna L1, Vecchione C, Notte A, Cordenonsi M, Dupont S, et al. (2006) Emilin1 links TGF-beta maturation to blood pressure homeostasis. Cell 124: 929-942. [Crossref]

18. Matsuki K, Hathaway CK, Lawrence MG, Smithies O, Kakoki M (2014) The role of transforming growth factor betal in the regulation of blood pressure. Current Hypertension Reviews 10: 223-238. [Crossref]

19. Sista AK, O’Connell MK, Hinohara T, Oommen SS, Fenster BE, et al. (2005) Increased aortic stiffness in the insulin-resistant Zucker fa/fa rat. Am J Physiol Heart Circ Physiol 289: H845-H851. [Crossref]

20. Cannaerts E, van de Beek G, Verstraeten A, Van Laer L, Loeys B (2015) TGF- $\beta$ signalopathies as a paradigm for translational medicine. Eur J Med Genet 58: 695-703. [Crossref]

21. Bertoli-Avella AM, Gillis E, Morisaki H, Verhagen JM, de Graaf BM, et al. (2015) Mutations in a TGF- $\beta$ ligand, TGFB3, cause syndromic aortic aneurysms and dissections. J Am Coll Cardiol 65: 1324-1336. [Crossref]

22. Gillis E, Van Laer L, Loeys BL (2013) Genetics of thoracic aortic aneurysm: at the crossroad of transforming growth factor-beta signaling and vascular smooth muscle cell contractility. Circulation Research 113: 327-340. [Crossref]

23. Jones JA, Spinale FG, Ikonomidis JS (2009) Transforming growth factor-beta signaling in thoracic aortic aneurysm development: a paradox in pathogenesis. Journal of Vascular Research 46: 119-137. [Crossref]

24. Frutkin AD, Otsuka G, Stempien-Otero A, Sesti C, Du L, Jaffe M, et al. (2009) TGF[beta]1 limits plaque growth, stabilizes plaque structure, and prevents aortic dilation in apolipoprotein E-null mice. Arterioscler Thromb Vasc Biol 29: 1251-1257. [Crossref]

25. Lin F, Yang X (2010) TGF- $\beta$ signaling in aortic aneurysm: another round of controversy. $J$ Genet Genomics 37: 583-591. [Crossref]

26. Nataatmadja M, West M, West J, Summers K, Walker P, Nagata M, et al. (2003) Abnormal extracellular matrix protein transport associated with increased apoptosis of vascular smooth muscle cells in marfan syndrome and bicuspid aortic valve thoracic aortic aneurysm. Circulation 108: 329-334. [Crossref]

Copyright: (C2016 Rabkin SW. This is an open-access article distributed under the terms of the Creative Commons Attribution License, which permits unrestricted use, distribution, and reproduction in any medium, provided the original author and source are credited. 